\title{
Does MR Sialography Have A Greater Diagnostic Accuracy Than Conventional X-Ray And Digital Subtraction Sialography In Detecting Salivary Glands Disease? A Literature Review.
}

\section{S M Uddin}

\author{
Shaukat Khanum Memorial Cancer Hospital and Research centre Johar Town, Lahore, \\ Pakistan
}

\begin{abstract}
Aim: The main aim was to determine the diagnostic accuracy of MR Sialography as compared to conventional $\mathrm{x}$-ray and digital sialography in detecting salivary gland diseases on the basis of research evidences available in the literature.

Description: It is noticed that almost all people develop illness of salivary glands at some stage of their lives. The major effects on salivary glands become evident as stones; infection tumors which may also involve related organs. Imaging methods like Ultrasound, Computed Tomography (CT) and Digital subtraction sialography (DSS) are used for assessment of parotid, sub-mandibular and sub-lingual glands in addition to conventional x-ray sialography which is marked as a gold standard for salivary glands assessment. Due to the non-invasive nature and level of comfort, MR Sialography is now being considered as an advanced technique for the detection of stones and tumor spread in the soft tissues with no risk of radiation exposure.

Methods and Results: Different databases which include Science direct, CINAHL, Ebesco Host, PubMed, Swetswise, Wiley Interscience, sage pub, and The Cochrane library were explored to get published literature. Total 10 studies were included and critically appraised under critical appraisal skills programme (CASP) tool.

Conclusion: The review proposed that though the use of MRS as the only diagnostic examination is useful but X-ray sialography remains the standard investigation tool due to its higher spatial resolution. MRS can be utilized as an alternative imaging technique by using special MR sequences such as 3D CISS and RARE where x-ray sialography cannot be performed.
\end{abstract}

Key words: MR Sialography, diagnostic accuracy of MR sialography, Conventional and MR Sialography, Review on MR Sialography.

\section{Introduction}

There are three types of major salivary glands which include Parotid (anterior to the ears), Sub-mandibular (below the mandible)

Correspondence to: Mr. Shavaiz Mohey Uddin, H-No A-7, Zila council colony, Luddan Road, District Vehari, Pakistan.Email:shavaiz786@yahoo.com
My and Sub-lingual (below the tongue) as described by Tripathi 1 . Beenken et al. 2 and ers and Ferris 3 described that parotid gland pathology accounts for $(70 \%)$ of all salivary gland disorders. Speight and Barrett ${ }^{4}$ described that incidence of salivary gland disorders in the western region is about (2.53.0 per 10000 per year). However, HornRoss et al. ${ }^{5}$ described that prevalence of 
salivary gland disorders is increasing annually at the rate of (1.1\%) in men across the world. The incidence of salivary gland cancer described by Sun et al. ${ }^{6}$ is $(0.9 \%$ per 10000 per year) worldwide. Mafee et al. described different methods of imaging the salivary glands which included computed tomography (CT), magnetic resonance imaging (MRI), ultrasound (US), Sialoendoscopy, radionuclide scintigraphy, $\mathrm{x}$-ray sialography and digital subtraction sialography (DSS). However, (CT) use has become limited in modern radiology due to radiation as per Rudack et al. ${ }^{8}$. Radionuclide scintigraphy as reported by klutmann ${ }^{9}$ and Sialoendoscopy as by Nahlieli et al. ${ }^{10}$ are also used for salivary imaging. European commission ${ }^{11}$ and Marchal and Dulgeuorv 12 marked $\mathrm{x}$-ray and digital sialography as the 'gold standard' for visualization of salivary glands. Jager et al. ${ }^{13}$ reported that $\mathrm{x}$-ray sialography requires an experienced operator for duct cannulation which has also been considered necessary by Gadodia et al. 14. It has been stated by Weissman 15 conventional methods produce problem due to patient motion, superimposition of the facial bones and contrast agent reactions. Ultrasound has been recommended as first line of investigation by Alyas et al. ${ }^{16}$ and Katz et al. ${ }^{17}$ but again its use is limited due to operator dependency. The use of MR Sialography (MRS) has been stated by Lomas et al. ${ }^{18}$ which reported the successful use of MRS for evaluation of salivary glands. Tonami et al. ${ }^{19}$ and Gadodia et al. ${ }^{14}$ suggested that MRS has the advantage of revealing both the ductal and parenchymal changes along the salivary glands without exposure to radiation. The only disadvantages of MRS as described by Becker et al. ${ }^{20}$ included the motion artefacts and long scan time. Since there is no consensus regarding the use of MRS as the only imaging investigation so the review was conducted to find an ideal diagnostic modality for assessment of salivary glands.

\section{Materials and Methods}

The research question was formulated by using the Population (Salivary glands patients), intervention (MR Sialography technique), comparison (Conventional sialography techniques), and Outcome (Diagnostic accuracies of both modalities) criteria as all four elements formulate a good question as by Houser ${ }^{21}$. Searched terms included salivary glands patients, salivary dysfunction, MR Sialography, x-ray sialography, digital sialography, diagnostic accuracy of MR Sialography, usefulness of MR Sialography. Different databases were explored which include PubMed, Sage Pub, The Cochrane library, Wiley Interscience, The science Direct, Ebesco, Swetswise and search engines which include Google, about, all the web, NHS evidence, Library resources reference lists were consulted to find appropriate articles for review.An inclusion and exclusion criterion included the studies conducted on Humans only, english language articles, research based studies, X-ray or digital sialography as a reference standard. Articles in other languages have to be excluded; incomplete studies and comparison with other standards were not included for preserving value of the literature review. (19) Articles from Cinahl, (32) from PubMed, (2) from the Cochrane library, (120) from science direct, (20) from Wiley Interscience, (83) from Swetswise, (26) from Research gate and (76) from Google scholar were found at initial search. A total of 10 studies were finally included for this review after applying the inclusion and exclusion criteria. Goodman and Moule 22 described that critical appraisal of the literature helps in identifying the gaps in research. The (CASP) tools were acquired from solutions for public health ${ }^{23}$ website and were applied to all the studies to assess 
Table 1: Brief findings of Conventional (x-ray and digital) and MR Sialography included in the review.

\begin{tabular}{|c|c|c|c|c|}
\hline Research Study & $\begin{array}{c}\text { X-ray } \\
\text { Sialograph } \\
\text { y provides } \\
\text { useful } \\
\text { information }\end{array}$ & $\begin{array}{c}\text { X-ray } \\
\text { Sialography } \\
\text { should be } \\
\text { replaced }\end{array}$ & $\begin{array}{l}\text { MR alone } \\
\text { considered } \\
\text { adequate }\end{array}$ & $\begin{array}{c}\text { Can MR } \\
\text { Sialography } \\
\text { correctly } \\
\text { identify patients } \\
\text { having } \\
\text { symptomatic } \\
\text { salivary } \\
\text { disorders? }\end{array}$ \\
\hline Lomas et al. $^{18}$ & Agree & Agree & To limited extent & Agree \\
\hline Heverhagen et al. ${ }^{24}$ & Agree & Agree & Agree & Agree \\
\hline Ohbayashi et al. ${ }^{25}$ & Agree & Agree & Agree & Agree \\
\hline Varghese et al. ${ }^{28}$ & Agree & Disagree & Disagree & $\begin{array}{c}\text { Somewhat } \\
\text { Agree }\end{array}$ \\
\hline Becker et al. ${ }^{20}$ & Agree & Agree & Agree & Agree \\
\hline Jager et al. $^{13}$ & Agree & Agree & Agree & Agree \\
\hline Kalinowski et al. ${ }^{29}$ & Agree & Somewhat Agree & To limited extent & Agree \\
\hline Tomiita et al. $^{26}$ & Agree & Agree & Disagree & $\begin{array}{c}\text { Somewhat } \\
\text { Agree }\end{array}$ \\
\hline Takagi et al. ${ }^{27}$ & Agree & Agree & Agree & Agree \\
\hline Gadodia et al. ${ }^{14}$ & Agree & Agree & Agree & Agree \\
\hline
\end{tabular}

strengths, limitations and quality of included evidences.

\section{Results and Discussion}

Out of ten studies included in this review, 8 report the adequacy of the MR alone in correct identification of salivary gland disorders.

The

findings are tabulated in the table 1 . Lomas et al. ${ }^{18}$ presented case reports of $n=3$ patients in which MRS added additional information for calculus. The results of the above study are however not representative of the patient population since there was a sample selection bias due to the representation of only $n=3$ cases. This study occupies a very low level in hierarchy of evidence to answer the proposed question.

Heverhagen et al. ${ }^{24}$ prospectively determined utility of MR Sialography against digital sialography in $n=16$ patients suspected of having sialadenitis and sialoliths. The authors found MRS to be comparable with the DSS for detecting sialadenitis in all cases. (03) Studies prospectively observed the efficacy of MRS in staging of Sjogren's syndrome. A prospective comparative study conducted by Ohbayashi et al. $^{25}$ described that MRS proved useful for staging of Sjogren's syndrome in $n=35$ patients. The sensitivity, specificity and accuracy of MRS in determining stage (I) disease were found to be $100 \%$. $92 \%$ and $91 \%$ in stage (II), $83 \%$ stage (III) disease and $100 \%$ stage (IV). Xray sialography and MRS findings correlated well having $(p<.001$ spearman rank correlation test). Similarly, the findings of MRS and x-ray sialography stages were reported to have a good correlation i.e. $(\mathrm{p}=$ $0.005)$ with Pearson correlation value of $(0.85)$ by Tomiita et al. ${ }^{26}$. The study suffered from a combination of selection and 

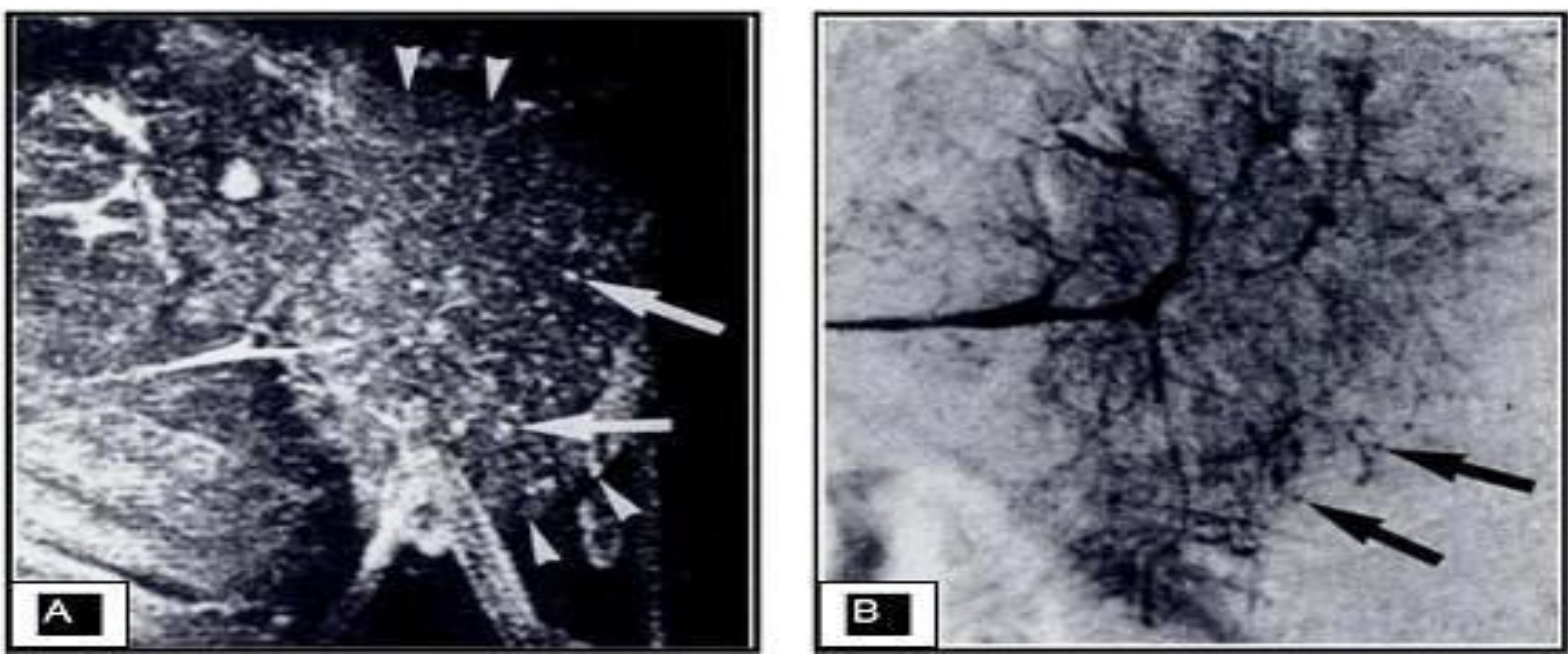

Figure: 1 (A) MR Sialogram obtained from a 25 years old woman depicts first and second order branches. Figure: 1 (B) Same patient X-ray Sialography demonstrated up to fourth order branches. (Ohbayashi et al ${ }^{25}$ )
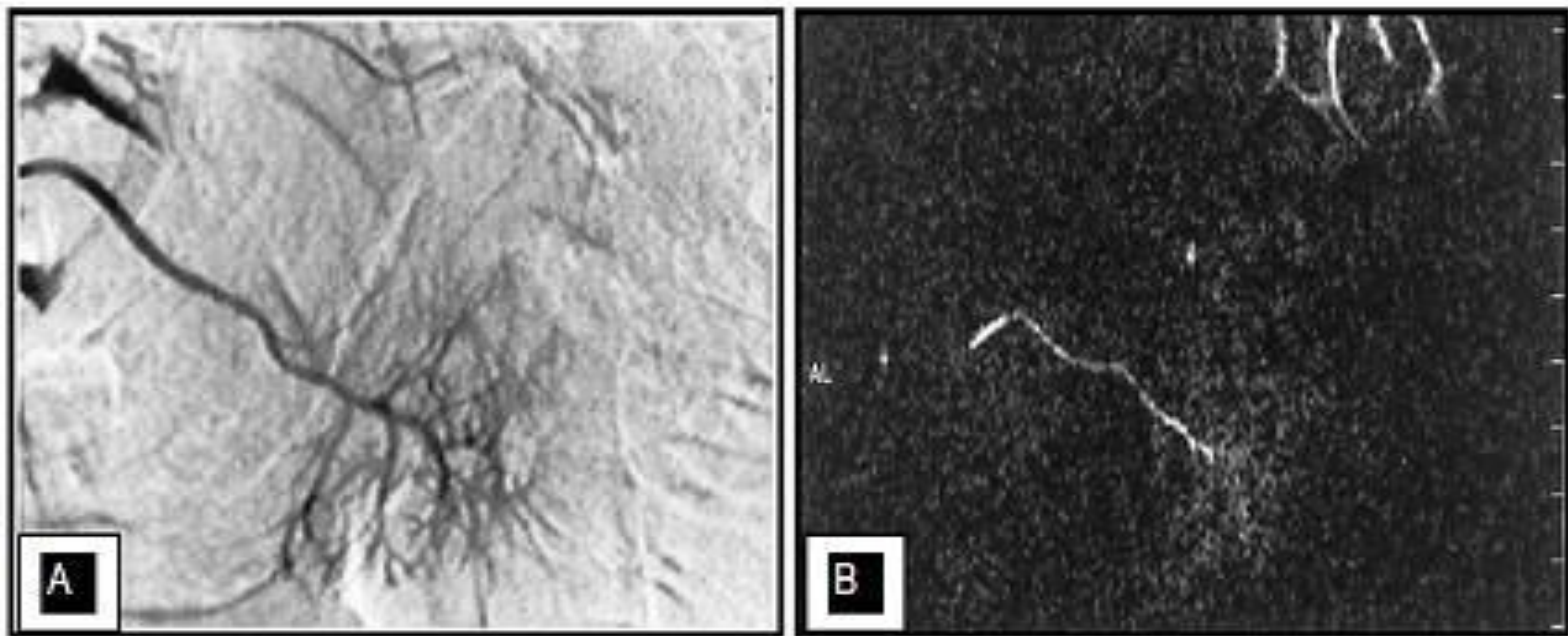

Figure: 2(A) Digital subtraction Sialogram obtained from a 61 years old woman demonstrated peripheral branches more clearly in parotid gland. Figure: 2(B) spatial resolution limited to first and second order branches in case of MR Sialogram of same patient. (Kalinowski et al ${ }^{29}$ )

review bias because it represented only a small cohort of patients i.e. (8) (all females) which possibly limited its strength. Another prospective study by Takagi et al. ${ }^{27}$ in patients $(n=143)$ also confirmed a good correlation i.e. $(\mathrm{p}<0.0001$ using spearman correlation test) between the stages of MRS and x-ray sialography.
Jager et al. ${ }^{13}$ using the 3-dimensional constructive interference (3D CISS) found MRS to be superior having $(p<0.05)$ than the rapid acquisition relaxation enhancement (RARE) sequence. The sensitivity of 3D CISS MRS for detecting sialoliths was found to be $(100 \%)$ and a specificity of $(80 \%)$ as compared to RARE sequence where sensitivity reduced to $(80 \%)$ and specificity 
was $(100 \%)$. The study is subjected to review and spectrum bias as simple MR imaging of desired area was also performed before sialography that might increased the sensitivity and specificity of MRS in detecting salivary disorders. Gadodia et al. 14 using 3D CISS sequence reported a sensitivity of $87 \%$ and specificity of $100 \%$ in $\mathrm{n}=28$ patients. The authors also performed imaging on Half fourier single shot turbo spin echo (HASTE) and found it $90 \%$ sensitive and $75 \%$ specific in diagnosing salivary disorders. Using a combination of CISS and HASTE, MRS achieved a sensitivity of $93 \%$ and specificity of $100 \%$. The overall sensitivity of MRS was $94.1 \%$ where as for $\mathrm{X}$-ray sialography it was $100 \%$ for different salivary disorders. Becker et al. ${ }^{20}$ investigated usefulness of 3-dimensional extended phase conjugate symmetry rapid spin echo (3D-EXPRESS) sequence in $\mathrm{n}=$ 61 and found that it was $91 \%$ sensitive and 94-97\% specific for calculi where as for stenosis reported sensitivity remained $100 \%$ and specificity $93-98 \%$. Additionally, MRS added useful information in $19 \%$ of glands of total 67 glands by detecting ranula and Warthin's tumour in $n=10$.

(02) Studies Varghese et al. ${ }^{28}$ and Kalinowski et al. ${ }^{29}$ don't recommend MRS as the only imaging investigation for identifying salivary disorders in patients. A prospective study by Kalinowski et al. ${ }^{29} \mathrm{n}=$ 80 showed that in acute sialadenitis DSS remained $100 \%$ sensitive and specific. MRS also showed same results with sensitivity and specificity of $100 \%$. In chronic sialadenitis DSS remained $96 \%$ sensitive and $100 \%$ specific and MRS proved to be $70 \%$ sensitive and 98\% specific. Moreover, DSS remained $90 \%$ sensitive and $98 \%$ for sialoliths as compared to MRS with a sensitivity of only $80 \%$ and specificity of $98 \%$. DSS was deemed necessary due to inability of MRS to show secondary and tertiary branches in most of the cases.

Results of a prospective study by Varghese et al. ${ }^{28}$ showed that $\mathrm{x}$-ray sialography depicted $100 \%$ accuracy for calculus where as MRS were $90 \%$ accurate. X-ray sialography was $100 \%$ accurate for stenosis where as MRS only 96\%. Similarly, MRS misclassified a proximal stricture as midduct stricture in $\mathrm{n}=1$ and did not show a micro-calcification in $n=1$. The sensitivity, specificity, accuracy, positive predictive value (PPV) and negative predictive value (NPV) of MRS in detecting lesions were $88 \%, 88 \%, \quad 94 \%$ and $78 \%$ which significantly improved to $100 \%, 88 \%, 96 \%$, $94 \%$, and $100 \%$ by using x-ray sialography images as controls. All of the studies except Kalinowski et al. ${ }^{29}$, Takagi et al. ${ }^{27}$, and Varghese et al. ${ }^{28}$ suffered from a combination of selection, spectrum and review biases. Only the studies by Gadodia et al ${ }^{14}$, Heverhagen et al. ${ }^{24}$, Lomas et al. ${ }^{18}$ and Tomiita et al. ${ }^{26}$ have accounted limitations. MRS didn't provide some useful clinical information that was only available with the help of conventional sialography or DSS. Almost all primary and secondary branching system was found to be visualized in case of MR Sialography as reported by all the studies. No Tertiary branching system was visualized on MRS as reported by all studies. In case of X-ray sialography Primary secondary and tertiary branching system all was visualized.

MRS revealed visualization of main branches and salivary duct up to second order branches (Fig. 1 \& Fig. 2). The other major factor limiting the use of MRS as the only diagnostic examination was the reported number of false positive and false negative as 2 false positive findings as strictures and 4 false negative findings as calculus reported by Varghese et al. ${ }^{28}$. Gadodia et al. ${ }^{14}$ reported 3 false negatives and 1 false positive finding were noted in 4 glands evaluated by HASTE and 4 false negative findings were noted in case of 3D CISS sequence. Becker et al. ${ }^{20}$ reported 4 false positive findings as Stenosis and 3 false negative as stones on 3D EXPRESS imaging. Similarly, Jager et al. ${ }^{13}$ reported 1 
false positive finding on 3D CISS in which stenosis was detected as a sialolith and sialoliths were overlooked on $n=3$ patients on RARE sequence.

The studies by Tomiita et al. ${ }^{26}$, Ohbayashi et al. ${ }^{25}$ and Takagi et al. ${ }^{27}$ reported that MRS findings correlated well with $\mathrm{X}$-ray sialography in staging of Sjogren's syndrome but owing to poor spatial resolution in MRS; differences were noted in stages determined by MRS and x-ray sialography as lower and higher in $6 \%$ and $10 \%$ patients respective to studies. Kalinowski et al. ${ }^{29}$ reported that the sensitivity and specificity of MRS in diagnosing sialadenitis remained $100 \%$ which was comparable to DSS i.e. $100 \%$. Moreover, the accuracy of MRS in diagnosing calculus remained $100 \%$ by using a combination of 3D CISS and HASTE sequence as reported by Gadodia et al. ${ }^{14}$. These findings suggested that MRS can be recommended as an alternative to $\mathrm{X}$ ray sialography because MRS and DSS results correlated well with each other.

The review of collected studies has highlighted the absence of universally accepted criteria for using MRS. For a fact that changing the parameters significantly improves the spatial resolution, a wide variation has been observed between the research studies due to different parameters used for MRS. Moreover, the use of special sequences such as (CISS, HASTE, EXPRESS and RARE) can only be applicable to selected centres having this facility. For a general acceptance of MRS, efforts could be made to improve the resolution by keeping the scanner capacity i.e. field strength constant or at least choosing almost the same parameters for maintaining the internal validity. Secondly, no study paid attention to the increased cost resulting from the use of MRS as the only investigation tool for salivary glands.

\section{Conclusion}

In the light of evidences presented in this review, the use of MRS as the only diagnostic examination could not be justified. A wide variation of parameters and given number of false positive and false negative results reported by different studies may limit generalizability and reproducibility of using MRS as the only investigation tool. All the centres intending to replace x-ray sialography with MRS must take extensive research to generate a valid and reproducible investigation protocol. The results of this review might be subject to publication bias since only the articles were confined to English language were included because it was not feasible to assess studies in a foreign language. Moreover, any study published earlier than 1995 was not included since the quality of MRI has markedly improved over the last few years in terms of software, hardware and image resolution. Discussion on other imaging investigations like ultrasound, $\mathrm{CT}$ and radionuclide scintigraphy was excluded because it was beyond the scope of this literature review.

Thus, x-ray sialography remains the standard investigation tool primarily for diagnosis of salivary disorders. MRS can be utilized as an alternative imaging using 3D CISS and HASTE sequences where $x$-ray sialography fails to provide a definite diagnosis.

\section{Acknowledgement}

The author would like to warmly thank Dr. Natasha Anwar of Shaukat Khanum Cancer Hospital for his kind support in making this literature review successful. The author would also like to appreciate all the supporters who guided the researcher accordingly.

\section{References}

1. Tripathi Y. Concise textbook of Physiology for dental students. $2^{\text {nd }}$ ed. New Delhi: Elsevier; 2007. 
2. Beenken SW, Urist MM, Casiano R. 2011 Salivary Gland Tumours [Internet]. Moscow: Armenian Medical Network; [updated 2006 Jul 8; cited 2011 Feb 11].

3. Myers EN, Ferris RL. Salivary gland disorders. $1^{\text {st }}$ ed. Berlin: Springer; 2007.

4. Speight PM, Barrett AW. Salivary gland tumours. Oral Dis. 2002 Sep 10; 8 (5): 229-240.

5. Horn-Ross PL, Ljung BM, Morrow M. Environmental Factors and the risk of Salivary gland Cancer. Epidemiology. 1997 Jan 24; 8 (4): 414-419.

6. Sun EC, Curtis R, Melbye M, Goedert JJ. Salivary glands cancer in the United States. Cancer Epidemiol Biomarkers Pre. 1999 Oct 25; 8 (12):1095-1100.

7. Mafee MF, Valvassori GE, Becker M. Imaging of the head and neck. 2nd ed. Stuttgart: Thieme publications; 2005.

8. Rudack C, Jorg S, Kloska S, Stoll W, Thiede O. Neither MRI, CT nor US is superior to diagnose tumours in the salivary glands- an extended case study.

Head Face Med. 2007 Apr 3; 3 (19):18.

9. Klutmann S, Bohuslavizki KH, Kroger S, Bleckman C et.al. Quantitative salivary gland scintigraphy. J Nucl Med Technol. 199925 Mar; 27 (1):2026.

10. Nahlieli O, Nakar LH, Nazarian Y, Turner MD. Sialoendoscopy: A new approach to salivary gland obstructive pathology. J Am Med Assoc. 2006 1st Oct; 137 (10):1394-1400.
11. European Commission. Radiation protection 118 referral guidelines for Imaging. Luxembourg: European commission; 2001.

12. Marchal F, Dulguerov P. Sialolithiasis Management: state of the art. Arch Otolaryngol Head Neck Surg.2003 Sep 6; 129 (9):951-956.

13. Jager L, Menauer F, Holzknecht $N$ et.al Sialolithiasis: MR Sialography of the Submandibular duct--An Alternative to Conventional Sialography and US? Radiology. 2000 Feb 22; 216 (3):665671.

14. Gadodia A, Seith A, Sharma R, Thakar A, Parshad R. Magnetic resonance sialography using CISS and HASTE sequences in inflammatory salivary gland diseases: Comparison with digital sialography. Acta Radio. 2010 Mar 5th; 51(2):156-163.

15. Weissman JL. Imaging of the Salivary Glands. Semin Ultrasound CT MR. 1995 Dec 11; 16 (6):546-568.

16. Alyas F, Lewis K, Williams M, Moody AB, Wong KT, Ahuja AT, Howlett DC. Diseases of the Submandibular gland as demonstrated using high resolution ultrasound. $\mathrm{Br} \mathrm{J}$ Radiol. 2005 Apr 1st; 78 (3): 362 -369.

17. Katz P, Hartl DM, and Geurre A. Clinical ultrasound of the salivary glands. Otolaryngol Clin North A. 2009 Dec 11; 42 (6):973-1000.

18. Lomas DI, Carroll NR, Johnson G et.al. MR Sialography: Work in progress. Radiology. 1996 March 18; 200 (1):129-133.

19. Tonami H, OgawaY, Matoba M, and Sugai, S. MR Sialography in patients 
with Sjogren's syndrome. Am J Neuroradiol. 1998 August 25; 19 (7):1199-1203.

20. Becker M, Marchal F, Becker CD, Dulgeurov P, Georgakopoulos G, Lehmann W, Terrier F. Sialolithiasis and Salivary Ductal Stenosis: Diagnostic Accuracy of MR Sialography with a Three-dimensional Extended-Phase Conjugate-Symmetry Rapid Spin-Echo Sequence. Radiology. 2000 Nov 19; 217 (2):347-358.

21. Houser J. Nursing Research: Reading, using and creating evidence. $1^{\text {st }}$ ed. London: Jones and Bartlett publishers; 2008 .

22. Goodman M, Moule P. Nursing Research: An introduction. $1^{\text {st }}$ ed. London: Sage publications Ltd; 2009.

23. Solutions for Public Health SPH. Critical Appraisal Skills programme tools. [Internet]. Oxfordshire: Solutions for Public Health; [updated 2011 Jan 6th cited 2011 Feb 18]. Available from: http://www.sph.nhs.uk/what-wedo/public-healthworkforce/resources/criticalappraisals-skills-programme.

24. Heverhagen JT, Kalinowski M, Rehberg E, Klose KJ, Wagner HJ.. Prospective Comparison of Magnetic Resonance Sialography and Digital Subtraction sialography. J Magn Reson Imaging. 2000 May 12; 11 (5): 518524.

25. Ohbayashi N, Yamada I, Yoshino N, Sasaki T. Sjogren syndrome: comparison of assessments with MR Sialography and conventional sialography. Radiology. 1998 Dec 12; 209 (3):683-688.
26. Tomiita M, Ueda T, Nagata H, Tanabe E, Shimojo N, Saito K, Motoori K, Ito $\mathrm{H}$, Kohno Y. Usefulness of magnetic resonance sialography in patients with juvenile Sjogren's syndrome. Clin Exp Rheumato. 2005 Jul 29; 23 (4):540544.

27. Takagi Y, Sumi M, Cauteren MV, Nakamuru T. Fast and High Resolution MR sialography using a small surface coil. J Magn Reson Imaging. 2005 Jun 21; 22 (1):29-37.

28. Varghese JC, Thornton F, Lucey BC, Walsh M, Farrell MA, Lee MJ. A prospective comparative study of MR Sialography and conventional sialography of salivary duct disease. Am J Roentgenol. 1999 Dec 14; 173 (6):1497-1503.

29. Kalinowski M, Heverhagen JT, Rehberg E, Klose KJ, Wagner HJ. Comparative study of MR Sialography and digital subtraction sialography for benign salivary gland disorders. Am J Neuroradiol. 2002 Oct 10; 23 (9):14851492.

30. Kalinowski M, Heverhagen JT, Rehberg E, Klose KJ, Wagner HJ. Comparative study of MR Sialography and digital subtraction sialography for benign salivary gland disorders. [Photograph 3]. Am J Neuroradiol. 2002 Oct 10; 23 (9):1485-1492.

31. Ohbayashi N, Yamada I, Yoshino N, Sasaki T. Sjogren syndrome: comparison of assessments with MR Sialography and conventional sialography. [Photograph 2]. Radiology. 1998 Dec 12; 209 (3):683-688. 